
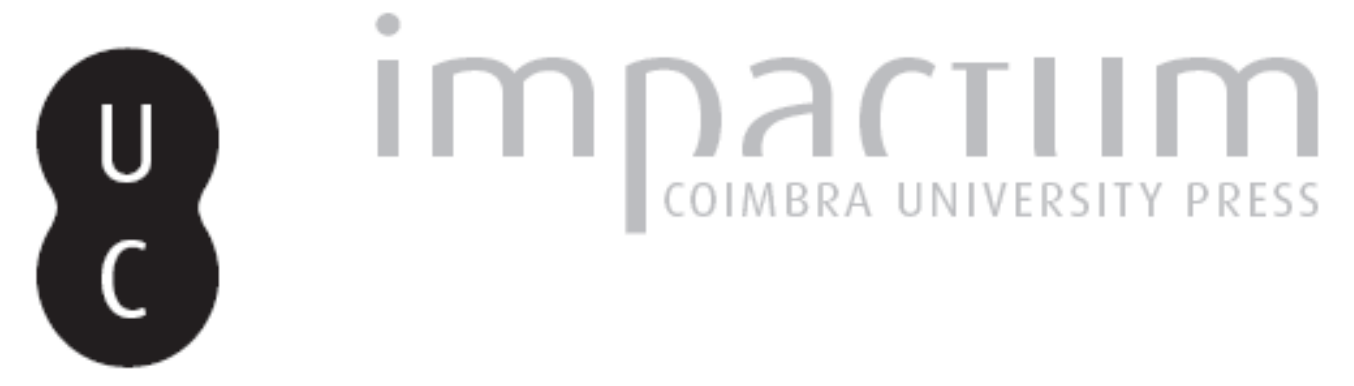

\title{
“Espelho meu, espelho meu, haverá alguém mais belo do que eu?": representações mediáticas da 'raça'
}

Autor(es): $\quad$ Marques, Sónia

Publicado por: Imprensa da Universidade de Coimbra

URL persistente:

URI:http://hdl.handle.net/10316.2/43230

DOI:

DOI:https://doi.org/10.14195/2183-5462_31_8

Accessed : $\quad$ 26-Apr-2023 12:51:35

A navegação consulta e descarregamento dos títulos inseridos nas Bibliotecas Digitais UC Digitalis, UC Pombalina e UC Impactum, pressupõem a aceitação plena e sem reservas dos Termos e Condições de Uso destas Bibliotecas Digitais, disponíveis em https://digitalis.uc.pt/pt-pt/termos.

Conforme exposto nos referidos Termos e Condições de Uso, o descarregamento de títulos de acesso restrito requer uma licença válida de autorização devendo o utilizador aceder ao(s) documento(s) a partir de um endereço de IP da instituição detentora da supramencionada licença.

Ao utilizador é apenas permitido o descarregamento para uso pessoal, pelo que o emprego do(s) título(s) descarregado(s) para outro fim, designadamente comercial, carece de autorização do respetivo autor ou editor da obra.

Na medida em que todas as obras da UC Digitalis se encontram protegidas pelo Código do Direito de Autor e Direitos Conexos e demais legislação aplicável, toda a cópia, parcial ou total, deste documento, nos casos em que é legalmente admitida, deverá conter ou fazer-se acompanhar por este aviso.

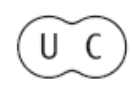




\section{Media Jornalismo}

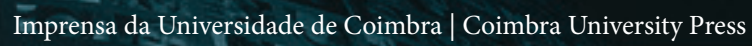

N. 31 Vol. 17, N. ${ }^{\circ} 2$ - 2017

Esia

(2) M MEDIA E DIVERSIDADE

लिखिएक

2)

*).

() (6) $3(9)$

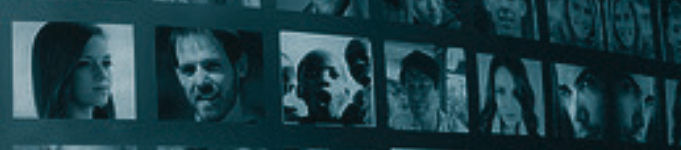

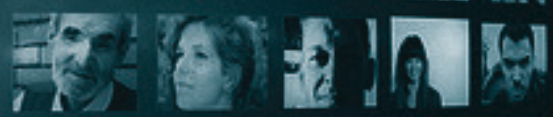

* a

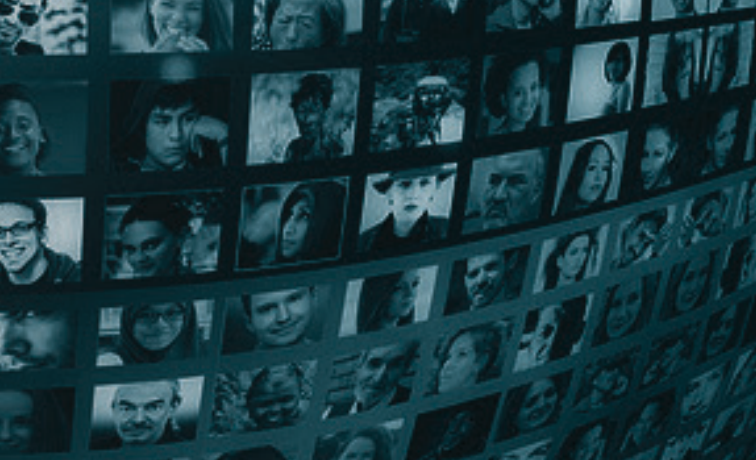

तथ 


\title{
"ESPELHO MEU, ESPELHO MEU, HAVERÁ ALGUÉM MAIS BELO DO QUE EU?" - REPRESENTAÇÕES MEDIÁTICAS DA 'RAÇA'
}

\author{
"MIRROR MIRROR ON THE WALL, WHO'S THE FAIREST OF \\ THEM ALL" - MEDIA REPRESENTATIONS OF RACE
}

\author{
SÓNIA MARQUES \\ Universidade de Coimbra, Faculdade de Letras, 3004-530 Coimbra, Portugal \\ sr.marques@gmail.com
}

Resumo

Este artigo tem como objetivo refletir sobre o conceito de representação e a sua articulação com o paradigma crítico dos estudos culturais, assim como discutir o papel dos órgãos de comunicação social na difusão de representações raciais, expressas nas categorias branco-negro. Sugere-se igualmente a promoção da literacia mediática e reflexividade, com vista ao aumento da consciência crítica dos recetores de mensagens veiculadas pelos media.

\section{Palavras-chave:}

Representação; estudos culturais; media; raça; literacia mediática

Abstract

This article aims to reflect on the concept of representation and its articulation with the critical paradigm of cultural studies, as well as to discuss the media role in the diffusion of 'racial' representations, expressed in the black-white categories. Guidelines are also suggested in order to promote media literacy and reflexivity, raising the critical awareness among media audiences.

KEYWORDS:

Representation; cultural studies; media; race; media literacy

\section{Conceito de Representação}

Não farás imagem em escultura nem representação alguma do que está em cima, nos céus, do que está debaixo da terra, nas águas. Não te prostrarás diante dessas coisas e não as servirás, porque Eu, o Senhor, teu Deus, sou um Deus zeloso, que castigo o pecado...

Bíblia, Êxodo 20: 4-6

Várias são as definições encontradas no dicionário para 'representação', desde "exibição", a "quadro, escultura ou gravura que reproduz uma coisa ou pessoa", até "corporação dos representantes de uma nação", mas "o que todos esses exemplos 
têm em comum é o princípio semiótico de que algo 'está no lugar' de uma outra coisa, ou de que alguém ou algum grupo está a falar em nome de outras pessoas ou grupos" (Shohat e Stam, 2006: 268).

Para podermos comunicar uns com os outros, necessitamos de materializar os nossos pensamentos num som, imagem, palavra ou gesto. Ao fazermos isso criamos um signo que, ao relacionar-se com outros signos, dá origem às diversas linguagens. Roland Barthes (2001) fala num processo contínuo de "semiosis" que origina o "mito" (p. 136-139).

A relação entre coisa - conceito - som/imagem/palavra/gesto é pois contingente, arbitrária, imotivada, tal como o é o significado daí decorrente, que repousa num "hábito coletivo" ou "convenção" (Saussure, 2006: 79). Esta lógica semiótica pode ser alargada a todo e qualquer fenómeno ou artefato cultural criador de significação (também designado de 'texto'), seja um objeto, pessoa, evento, real ou fictício, contemporâneo ou não.

A linguagem e os significados a ela associados são, desta forma, instáveis e transitórios, uma vez que são determinados pelos vários condicionantes espácio temporais históricos que participam no processo de codificação e descodificação. A teia de significados que armazenamos, consciente e inconscientemente, constitui o repertório de representações, o nosso 'senso comum'.

A representação é, assim, a produção de sentido através da linguagem, seja ela verbal, gestual, sonora ou imagética. 0 problema coloca-se na medida em que o mundo real não é fielmente refletido, captado, mimetizado na linguagem, o que gera uma relação conturbada. Não é por acaso que certos nativos indígenas se recusem a ser fotografados e a religião islâmica condene qualquer representação do profeta Maomé1. Ademais, uma vez que o significado de um signo é socialmente definido, percebe-se como um mesmo signo pode ser encarado de formas distintas. As diferenças culturais, nomeadamente as saudações, costumes e cores facultam bons exemplos. Outro aspeto que vem acicatar a discussão são as representações disseminadas em larga escala. 0 mundo é demasiado amplo, complexo e diverso, para que o ser humano, ao longo de uma vida, possa dar resposta à sua sede por informação e conhecimento, limitando-se apenas às relações diretas. Os media ajudam nesta apreensão e compreensão do mundo, mas a problemática em torno das representações é aqui aumentada, pois os produtos mediáticos, sejam eles informativos ou de entretenimento, reais ou ficcionais, não são neutrais. Por detrás das organizações existem pessoas e grupos com interesses particulares, nomeadamente 0 da manutenção do status quo e o do controle do discurso público. E mesmo

10 iconoclasmo (do grego eikon "ícone" e klastein "quebrar") quer dizer stricto sensu a destruição de representações, a guerra contra as imagens, seja ela decorrente de razões religiosas ou profanas. A preocupação inerente é a de que a imagem se torne um objeto de adoração, suplantando em importância e valor o que ela representa. 0 iconoclasmo foi responsável pela destruição de inúmeras obras de arte sacra, em várias religiões e em diversos períodos da história (Prata, 2014). 0 filme 'Exodus: Deuses e Reis' foi banido dos cinemas de Marrocos por conter uma representação de Deus, proibida segundo a lei islâmica. Crítica semelhante foi dirigida às caricaturas do Charlie Hebdo, que culminaram com 0 atentado, a 7 de Janeiro de 2015, à sede do jornal, em Paris, causando a morte a 12 pessoas (Notícias ao Minuto, 2014). 
que os textos não sejam criados com segundas intenções, a verdade é que elas (mesmo indiretamente e inconscientemente) acabam por estar lá presentes (Bernstein, 2002: 264).

Graças à capacidade repetitiva e persuasiva de expor informações e de criar representações verosímeis e pluridimensionais, isto é, passíveis de serem aplicadas em diversos contextos, as ideias veiculadas pelos media vão-se tornando normais, estabelecendo um padrão que influencia o modo como os indivíduos se veem a si próprios, o que os rodeia e a forma como se comportam (Gaines, 2010). Bernstein (2002) chama a atenção para um aspeto interessante: "Ouanto mais realismo as audiências percecionam num texto, menos chances há de questionarem as representações lá presentes [mas] o que deve ser sublinhado é que o realismo é uma mera convenção" (p. 262). Esta imposição de valores não é pois feita de um modo coercivo, mas sim subtil. Os pontos de vista tornam-se hegemónicos após confrontos que envolvem consentimento, resistência e negação.

\section{Os Estudos Culturais}

A ideia de representação foi amplamente abordada no paradigma crítico dos estudos culturais que, apesar de estar hoje disseminado um pouco por todo o lado, viu a sua institucionalização inicial ocorrer na Inglaterra, em 1964, na Universidade de Birmingham, através do Centre for Contemporary Cultural Studies. Na continuação dos estudos críticos de comunicação e cultura iniciados pela Escola de Frankfurt, os precursores da Escola de Birmingham Richard Hoggart, Stuart Hall, Raymond Williams e E. P. Thompson - estavam interessados em estudar os modos como as formas culturais serviam para aumentar a dominação social (de certas instituições como a família, a escola, a igreja, o trabalho, os media ou o estado) ou para possibilitar a resistência contra essa dominação, por parte de grupos subalternizados. 0 que os atraia era o que fora, até então, desprezado pela Academia: as experiências quotidianas das minorias. 0 primeiro foco incidiu nas classes trabalhadoras e suas subculturas, porém, as influências do feminismo, das lutas anti-racistas e dos fluxos migratórios obrigaram a dar atenção às questões de género, sexualidade, 'raça', etnia e nacionalidade (Hall, 1980; Miller, 2006; Wolton, 2012; Kellner, 2001).

\section{A QUESTÃo dA 'RAÇA'}

0 enfoque da 'raça' 2 não era ainda uma preocupação académica e social, no Reino Unido, nos anos 60. Tal alterou-se com o influxo de migrantes caribenhos e asiáticos, com as vozes críticas dentro do Centro e devido à influência dos estudos norte- americanos.

2 Note-se que o termo 'raça' raramente era usado durante o comércio de escravos, tornando-se recorrente no século XIX, onde se tornou sinónimo de "nação", sendo mais tarde reduzido às categorias "caucasiana", "mongolóide" e "negróide". Apesar da sua validade científica ter sido desacreditada com o desenvolvimento da genética, o termo continua vivo na linguagem quotidiana, quando se trata de distinguir indivíduos com base na aparência. 
Ao debruçar-se sobre as representações raciais, Hall (1992) notou que as narrativas mediáticas faziam muito mais do que espelharem ou distorcerem a realidade. Elas construíam o imaginário, as identidades e experiências das pessoas. Ele apercebeu-se igualmente do surgimento de uma nova forma de racismo cultural, caracterizada pela aliança entre a herança colonial, onde as pessoas eram vistas como menos civilizadas e inferiores, e novas práticas discriminatórias baseadas nos estilos de vida ${ }^{3}$.

Nas análises noticiosas que levou a cabo, Van Dijk (2000) reparou que as novas formas de racismo, mais 'democráticas' e 'respeitáveis', eram agora "discursivas", através do uso de palavras depreciativas, i.e., "palavras-código".

Hall (1992) sublinha que este tipo de racismo se expressa sobretudo através de uma "dupla-sintaxe". Mais do que a direta e agressiva discriminação, o crucial são as "profundas ambivalências", a "dupla estrutura" da representação, a capacidade de dizer duas coisas contraditórias ao mesmo tempo (p. 15,16). Daí que muitas das representações oscilem frequentemente entre a atração e a repulsa, "entre as fantasias de romance e ódio", havendo ocasiões em que a imagem, lettering e sonoridade pertencem a enquadramentos ideológicos diferentes (Ferguson, 2004: 82,86). Para Hall (1992), o conhecimento deveria ser procurado nas "ausências", nos "silêncios", no "imaginário à superfície a falar sobre um conteúdo indizível, do conteúdo reprimido de uma cultura" (p. 15-16).

Estes argumentos estão relacionados com a pluridimensionalidade das representações. É imprudente tentar encontrar-se em todos os produtos mediáticos, com elementos étnicos ou raciais, ideologias escondidas, ausências intencionais, realidades distorcidas ou práticas discriminatórias veladas. Eles tanto podem estar, como não estar, presentes, assim como tanto podem estar presentes para umas pessoas e não para outras ${ }^{4}$. Visto as mensagens serem polissémicas, os significados apreendidos pelas audiências ou leitores são múltiplos e contrastantes. Os indivíduos podem simultaneamente ser oprimidos e opressores, pois cada situação está sempre dependente do contexto em que se insere. E dentro de um mesmo grupo 'racial' podemos encontrar variações baseadas no género, classe, orientação sexual, religião, idade ou região (Weber, 1998: 28). Brooks e Hébert (2006) observam, por exemplo, que na indústria do hip hop norte-americana, as mulheres negras aparecem constantemente como objetos sexuais, sendo os vídeos produzidos maioritariamente por homens negros (p. 301).

3 Já o psiquiatra e filósofo da Martinica Frantz Fanon referira, em 1956, que o "objeto do racismo [cultural] é, não discriminar o homem particular, mas uma certa forma de existir" (p. 274).

4 Veja-se como o anúncio australiano, incluído na série 'Guia de sobrevivência do Cricket', da KFC (rede de restaurantes de comida rápida norte-americana) só foi conotado como preconceituoso depois de ter viajado até aos Estados Unidos (The Guardian, 2010). 


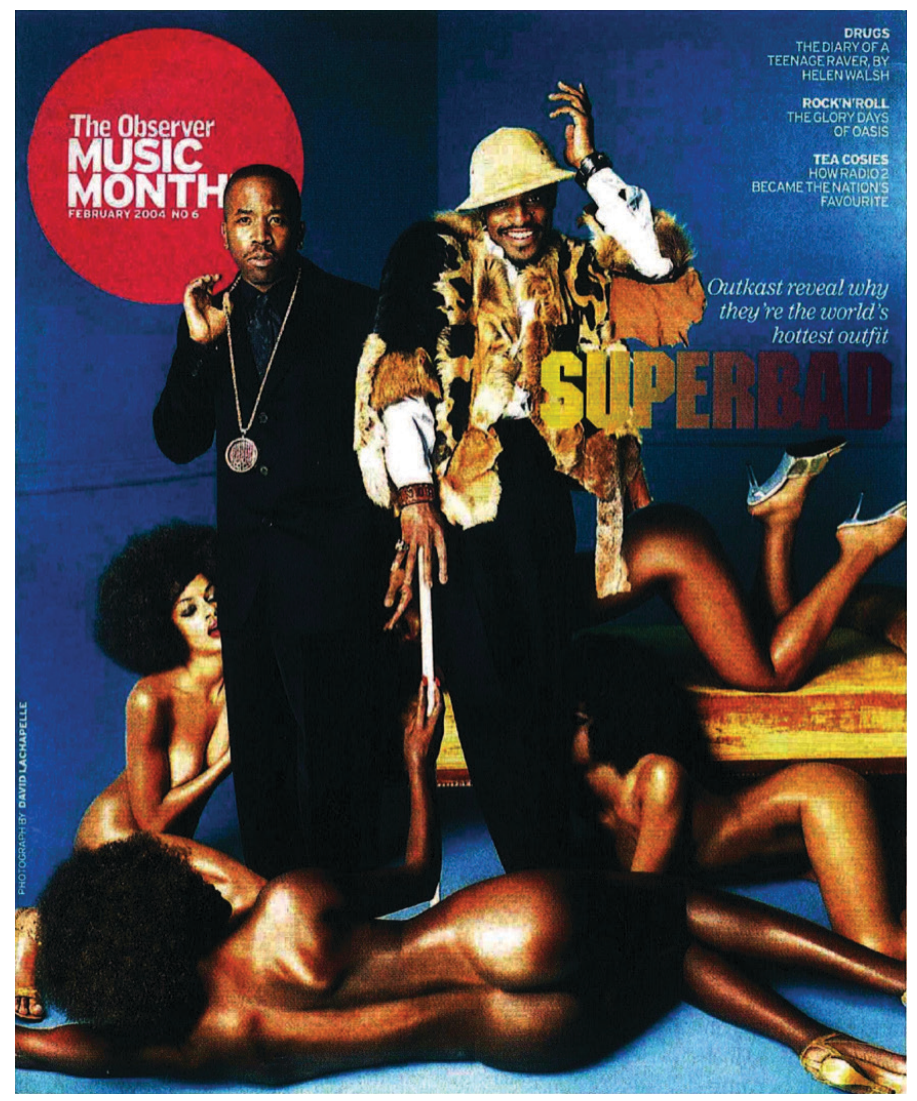

Figura 1. Capa da revista The Observer Music Monthly, February 2004, no. 6. In: Bennet et al., 2006: 102.

0 importante é possuirmos uma atitude crítica que espolete o que Gaines (2010) chama de "reação aha!" e que quebre com o hábito de aceitar, sem questionar, as representações mediáticas como realidade. 0 autor explica que um "travador de pensamento" é acionado quando o intérprete se depara com um signo que entra em conflito com a sua experiência ou noção de identidade. Assim, apesar de nem todas as representações raciais causarem essa "reação aha!", muitos desses signos conflituantes estão relacionados com as considerações seguintes.

\subsection{Branco | Negro}

A discussão em torno da 'raça' tende a centrar-se nas pessoas negras, comparativamente às brancas, embora grande parte dos argumentos possa alastrar-se a outros grupos. Ferguson (2004) refere que "ao representar certas formas de alteridade, é frequentemente necessário para os media estabelecerem a norma perante a qual se possa medir a relativa indesejabilidade do outro em questão" (p. 75). Nas representações da 'raça', a norma é a categoria 'branco', perante a qual todas as outras categorias (não-brancas) são comparadas. 
A superioridade branca não é afirmada, mas simplesmente presumida - os brancos são os objetivos, os especialistas, os que não causam problemas, aqueles que julgam, que estão "em casa" no mundo, aqueles cuja prerrogativa é criar leis que organizem a desordem (Shohat e Stam, 2006: 292).

Para Gallagher (2007), ser 'branco' é visto como "identidade social uniforme, imutável, incontestada e uma ocorrência natural, ao invés de algo que foi e continua a ser forjado no meio de contestação política, coerção e violência" (p. 10). 0 autor acrescenta que esse privilégio resulta do "alcance internacional dos media Ocidentais, da geopolítica, e da promoção dos padrões de consumo e estilos de vida 'brancos' à volta do globo " (ibid., p. 9).

Em 2014, o Conselho de Regulação Publicitária da Índia introduziu regras mais apertadas para as publicidades aos cosméticos clareadores, após queixas contra anúncios racistas que tendiam a exacerbar o estigma social já existente, num país onde a maior parte da população tem pele escura (Emmanuel, 2014). Mais recentemente, o slogan "Você só precisa ser branca para vencer", de um comercial de creme branqueador na Tailândia, gerou igualmente polémica e reacendeu o debate sobre racismo no país.

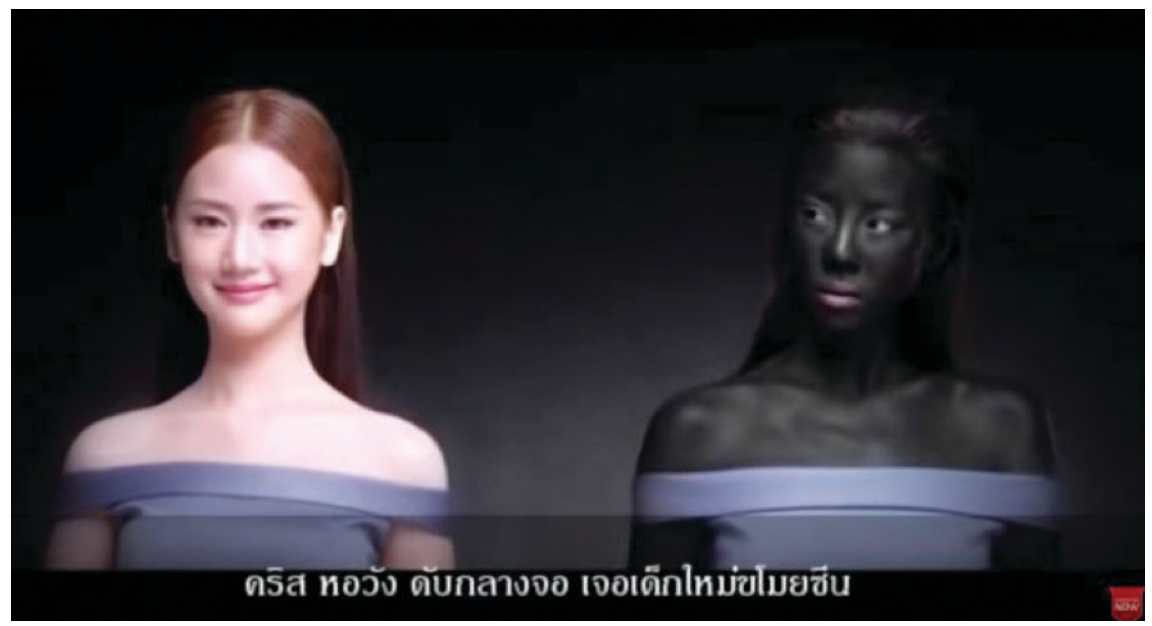

Figura 2. "Você só precisa ser branca para vencer", anúncio tailandês de creme clareador, 2016. In: Jardim, 2016.

A autora brasileira Zelinda Barros e colegas (2011) dão-nos conta de como a supremacia branca é visível em aspetos comezinhos do quotidiano:

"se tomarmos a sociedade baiana como exemplo, veremos que mesmo que uma pessoa não se identifique como sendo de raça negra, o seu cabelo ainda é considerado "ruim" por ser crespo, o que é uma expressão racializada, pois afirma a existência de um outro tipo de cabelo que é melhor ou "bom", o cabelo liso, do "branco" (p. 23).

Similarmente, por que tem a modelo e actriz portuguesa Ana Sofia Martins, na campanha da L'Oréal, de surpreendentemente, ao ponto de se transformar em slogan, necessitar de afirmar que tem "orgulho nos caracóis"? 


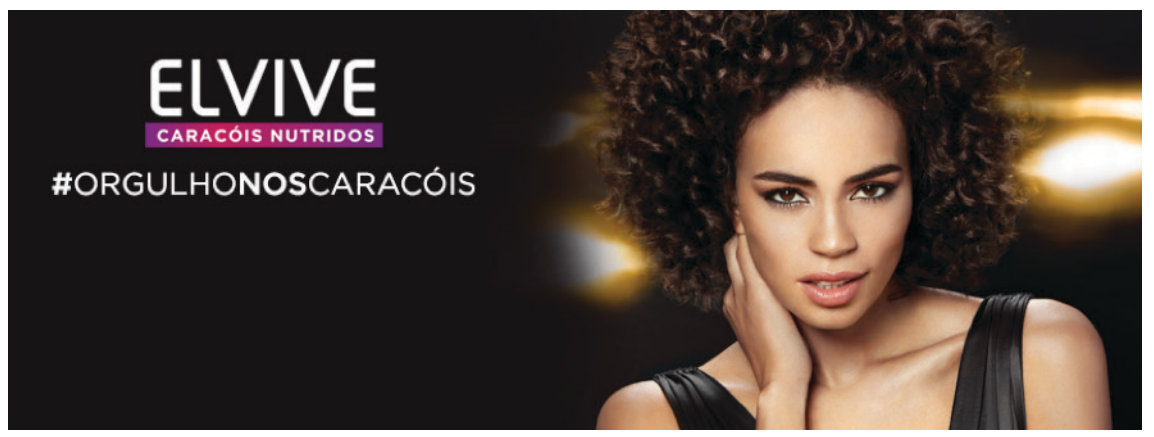

Figura 3. Ana Sofia Martins na campanha Elvive Caracóis Nutridos, da L'Oréal Paris, $2016^{5}$.

No sítio da Marketeer (2016), pode-se ler: «Ter cabelo com caracóis não tem de ser um pesadelo [...] A campanha [...] pretende dizer adeus à ditadura dos cabelos lisos e mostrar os caracóis como "símbolo de feminilidade e identidade"». E por que ter caracóis é um pesadelo? E por que até então os caracóis não eram vistos como "símbolo de feminilidade e identidade"? E por que têm de o ser?

Não será pois difícil de entender a controvérsia em torno da seguinte publicidade, que obrigou a multinacional alemã Nivea a um pedido público de desculpas (Visão, 2011).

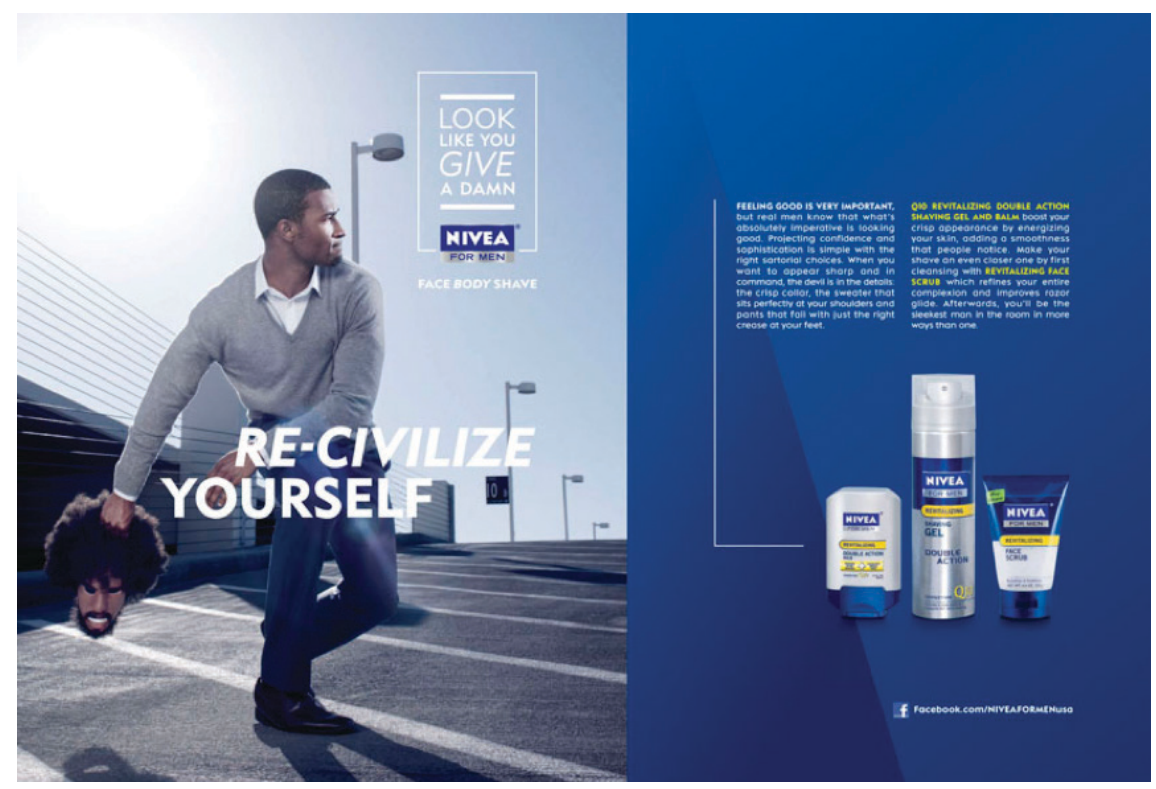

Figura 4. Anúncio da Nívea (“re-civiliza-te"), 2011. In: Visão, 2011.

5 In: (htp://missanasofia.com/tag/caracois/) (acedido 21/12/2016). 


\subsection{Exclusão | Estereotipagem | Assimilação}

Quando se fala em 'raça', é frequente os conceitos de exclusão, estereotipagem e assimilação emergirem. Para Ott e Mack (2014), a característica mais marcante das representações raciais nos Estados Unidos é a exclusão. "As minorias raciais simplesmente não "existem" em grande parte dos media que consumimos diariamente, e esta ausência reforça as estruturas ideológicas de poder ao sobre-representar o dominante grupo branco nos textos mediáticos", constatam os autores ( $p$. 51). Alternativamente, quando Ihes é dada visibilidade, frequentemente as 'pessoas de cor' são vítimas de estereótipos.

Há quase 100 anos Lippman já chamava a atenção para as vantagens do uso de estereótipos. Ao funcionarem como atalhos, condensavam informação, facilmente acessível e reconhecível, acerca do mundo em geral. 0 problema colocou-se quando se começou a olhar para os estereótipos como sendo a realidade, descurando 0 seu poder como veiculador de valores: "0 estereótipo está inevitavelmente ligado à ideologia porque efetivamente cria divisões entre grupos na sociedade. Tal está necessariamente ligado à hegemonia porque cria um consenso imaginado; que é, 'isto é o que nós pensamos deles'" (Jones e Jones, 1999: 106).

Os estereótipos são geralmente representações simplistas, onde um pequeno número de características são aumentadas a ponto de serem generalizadas a todo um grupo. Podem ser positivos ou negativos, mas associam-se frequentemente a ideias preconceituosas. No campo das representações estereotipadas, Jones e Jones (1999: 123) referem que o tipo de programas que enfatizam as minorias étnicas como "o outro" estão geralmente relacionados a viagens, música ou desporto. Aqui, acima de tudo, é acentuada a diferença através da celebração do exótico, frequentemente associado ao vestuário, culinária, arquitetura, sexualidade e beleza/ força física (Ferguson, 2004: 77). 0 exotismo não é mais do que a comercialização da 'diferença', a "especiaria, tempero que pode dar vida ao prato monótono que é a onipresente cultura branca" (Hooks, 1992: 21). 0 problema reside no fato de que ao "'exoticizar' um grupo racial, frequentemente retira-lhes a agência política contemporânea ao construí-lo como primitivo, pouco inteligente ou animalesco" (Ott e Mack, 2014: 158).

0 ponto aqui em destaque é o de que os negros são habitualmente louvados em atividades onde são requeridas qualidades físicas ao invés de intelectuais. $\mathrm{Na}$ ficção e no entretenimento, as representações de negros têm-se diversificado, contudo, nas notícias, apesar dos progressos, os negros continuam a ser associados a comportamentos criminosos e desviantes (Bernstein, 2002: 303). Outra tendência é a assimilação ou uma espécie de 'desracialização' das personagens (Brooks e Hébert, 2006). Os grupos minoritários surgem num ambiente socioeconómico mais favorável, mas que pouco tem a ver com as experiências quotidianas vivenciadas na realidade, numa perspetiva ironicamente designada de 'coco', 'banana' ou 'Oreo'; ou lidam com assuntos domésticos ou de trabalho leves, ficando

"as estruturas de desigualdade [... . escondidas por detrás de uma aparente "face" de diversidade. [... C. Consequentemente, os públicos poderão pensar que a generalizada pobreza Afro-Americana é o resultado da fraqueza individual ou deficiência cultural ao invés da opressão sistémica e ideológica" (Ott e Mack, 2014: 153,155). 


\subsection{Essencialismo | Associação | Categorização}

A noção de 'raça' continua a ser criticada pela sua padronização: "As pessoas negras não partilham a mesma identidade; identidades raciais são tão específicas, fragmentadas e contraditórias como qualquer outra identidade" (Bernstein, 2002: 310). Subjaz, aqui, um argumento antiessencialista que afirma que as identidades não são coisas imutáveis que podem ser encontradas, são sim construções discursivas, por vezes usadas como ferramentas de controlo social.

A desigualdade e opressão, presente nos discursos sobre a questão racial, manifesta-se concomitantemente em outros discursos subalternos relacionados com imigração, nacionalismo, sexualidade, religião, emprego, saúde e crime. Esses discursos das minorias têm sido "polarizados e biologizados", isto é, as categorias, vistas como fixas, permanentes, mensuráveis e naturais, são colocadas em polos assimétricos, onde de um lado encontramos, por exemplo, as categorias - branco, homem, heterossexual, bom, certo - e do outro - negro, mulher, homossexual, mau, errado, desconsiderando o que se encontra no meio. Um exemplo clássico de categorização conflituosa é o dos mestiços ou mulatos que, frequentemente, são vítimas de "coerção categórica" (Phillips, 2010:19).

\subsection{Raça | Racismo}

As pessoas, em geral, não se creditam como portadoras de atitudes racistas e preconceituosas, algo que consideram existir apenas entre os defensores da Extrema-Direita (Van Dijk, 1998: 34). Bonilla-Silva (2003) diz mesmo que vivemos numa era onde existe "racismo sem 'racistas'", onde "protegidos pela cegueira à cor, os brancos podem expressar ressentimento contra as minorias; criticar a sua moralidade, valores e ética de trabalho; e ainda reclamarem de serem vítimas de "racismo invertido". Ele dá o exemplo de como a segregação residencial se perpetua através da existência de práticas discriminatórias difíceis de detetar, como não serem mostrados, aos potenciais compradores negros, todos os imóveis disponíveis; serem-Ihes aplicadas rendas mais elevadas, não serem publicitados certos anúncios em zonas onde predomina um determinado grupo étnico; e ainda colocarem pessoas 'de cor' em posições pouco remuneradas ou com potencial de ascensão muito reduzido (p. 93-94). Também Van Dijk (2000) refere de que modo as estruturas e estratégias noticiosas contribuem para a sustentação de um racismo de elite, na medida em que "as primeiras 'definições da situação' e as primeiras opiniões [são] geralmente aquelas das autoridades ou de outras elites brancas" (p. 34).

Estes exemplos mostram como as formas de discriminação e segregação, anteriormente à vista de todos, foram sendo substituídas por outras mais subtis, dissimuladas, camufladas, profundas e estruturais e, por isso, mais perigosas, pois sendo difíceis de detetar, são igualmente difíceis de combater. Hall (1981) chama esta ideologia de "racismo inferencial", que assenta em representações que "permitem que os argumentos racistas sejam reformulados, sem nunca trazer à consciência os pressupostos racistas nos quais esses argumentos estão apoiados" (p. 20).

Vale a pena ainda ressaltar que a identificação e reconhecimento da conjuntura desfavorável que os grupos minoritários enfrentam têm consequências muito mais nefastas e permanentes ao nível micro, que frequentemente escapam à compreensão do cidadão comum. 
"Se eles acreditarem que o seu fracasso é resultado das suas limitações pessoais - falta de talento, desejo ou esforço - eles internalizam a opressão. Se, por outro lado, eles estão conscientes da natureza dominante da crença do sistema e das barreiras estruturais à obtenção do "ideal", eles resistem a internalizar a opressão e possuem potencial para uma autodefinição e autovalorização, um processo crítico para a sobrevivência dos grupos oprimidos" (Weber, 1998: 24).

\section{0 OUTRO LADO DO ESPELHO: RESPOSTAS À REPRESENTAÇÃO}

\subsection{LITERACIA MEdiáticA}

Uma das formas de munição contra representações nefastas ou, se não tanto, pelo menos, questionáveis, é a aposta na literacia mediática. 0 que se deseja não é que todos tenhamos um conhecimento académico de análise dos media mas, sim, que se desenvolva um olhar inquisidor, acerca do que vemos, ouvimos e lemos diariamente.

Assim, há alguns aspetos que devemos ter em atenção, como o fato de que a realidade veiculada pelos media é, de certa forma, parcial e incompleta. Particularizando o caso da televisão, que define como um "medium essencialmente realístico", Fiske (1987) explica que mesmo que exista uma realidade objectiva, o modo de a entender resulta dos códigos culturais.

E se esse bocado de realidade codificado é televisionado, os códigos técnicos e as convenções representacionais do medium são trazidos ao de cima de forma a torná-lo (a) tecnologicamente transmissível e (b) um texto cultural apropriado para as suas audiências" (p. 5).

E aqui reside a magia da televisão onde o "insignificante é exaltado pela imagem", onde a "simulação microscópica... faz o real passar para o hiper-real" (Baudrillard, 1991: 41). Porém, esta mediação acarreta um custo, daí que Baudrillard alerte para o "poder assassino das imagens, assassinas do real, assassinas do seu próprio modelo" (p.12). 0 que 0 autor quer dizer é que a fabricação de representações a partir de representações poderá, no limite, fazer com que não haja qualquer ligação entre a realidade primeira e as subsequentes, como uma espécie de parente muito afastado, com o qual já não temos qualquer ligação afetiva. "Já não se trata de imitação, nem de dobragem, nem mesmo de paródia. Trata-se de uma substituição no real dos signos do real, isto é, de uma operação de dissuasão de todo 0 processo real pelo seu duplo" (ibid., p. 9).

Os teóricos sociais propõem que se 'desnaturalizem' as representações mediáticas. Um valioso contributo é o conceito de 'desconstrução' atribuído a Jacques Derrida. 0 filósofo francês, associado ao pós-estruturalismo, procura "desconstruir os "estáveis" binários nos quais repousam o estruturalismo e a filosofia ocidental em geral, defendendo a "indecidibilidade" (fluidez das fronteiras) das oposições [...] hierárquicas como fala/escrita, realidade/aparência, natureza/cultura, razão/ loucura, etc., que excluem e desvalorizam a parte 'inferior' do binário." Pretende-se assim trazer ao de cima as suposições de um texto que frequentemente ficam enclausuradas na rigidez do binómio. "Um dos problemas centrais da desconstru- 
ção é que tem de usar a mesma linguagem concetual que pretende desconstruir" (Barker, 2000: 19, 32).

Numa sugestão semelhante, Hall (1981) alega que "uma das formas em que as lutas ideológicas ocorrem e as ideologias são transformadas é através da articulação dos elementos de uma forma diferente, produzindo assim diferentes significados: quebrando a corrente na qual estão atualmente fixadas" (p. 18).

Com base num método analítico semiótico, Gaines (2010:29-32) sugere alguns aspetos que se devem ter em atenção como:

- ver de que forma o medium em si mesmo influencia a natureza da comunicação;

- verificar quem está por detrás da codificação da mensagem e qual a sua intenção;

- separar os elementos distintivos do signo como o som, imagem, texto e aspetos específicos do contexto;

- notar se o significado é comunicado através de uma conexão real aos eventos ou objetos no mundo (índice), de uma semelhança com os objetos e eventos reais (ícone) ou através de uma convenção cultural (símbolo);

- distinguir entre denotação (significado literal e 'natural') e conotação (significado implícito e 'socialmente construído');

- dentro do âmbito conotativo, os valores, crenças e referências intertextuais explicitamente expressos, assim como os 'silêncios ideológicos'; e quais as possíveis consequências da interpretação destas suposições;

- apontar possíveis interpretações alternativas e refletir por que diferentes pessoas poderão interpretar os mesmo fenómeno de um modo oposto.

\subsection{Reflexividade}

Esta é uma daquelas máximas mais fáceis de definir na teoria do que aplicar na prática, uma vez que "retirar inferências... não é tanto um dom natural, mas uma longa e difícil arte" (Peirce, 1877). Também designada 'refletividade', consiste em "pensar acerca das coisas (distinto de responder automaticamente) e a monitorarmo-nos a nós mesmos" (Bruce e Yearley, 2006: 256). No caso de investigadores e cientistas sociais, o termo ganha uma dimensão acrescida pois refere-se a uma "reflexão auto consciente... acerca das condições através das quais a pesquisa é produzida, disseminada e recebida" (Matless, 2009: 627).

Durante uma conversa com um colega doutorando coloquei-lhe à frente a capa da revista Vogue, de Abril de 2008, onde aparecia o basquetebolista norte-americano James Lebron e a modelo brasileira Gisele Bündchen. À parte da foto ter sido tirada pela famosa Annie Leibovitz e de ser a primeira capa na história da revista com um homem afro-americano, questionei-o se via alguma coisa de relevante. Basicamente, ele disse que não. Mostrei-lhe então o cartaz a recrutar militares para a primeira guerra mundial e resumidamente contei-lhe que vozes críticas se ergueram contra a imagem, pela escolha de um desportista (mais uma vez) e onde era salientada a bestialidade e sexualidade dos negros através da exaltação de qualidades físicas (Ott e Mack, 2014: 153). Desta vez a resposta foi diferente e pude ver a "reacção aha!" 

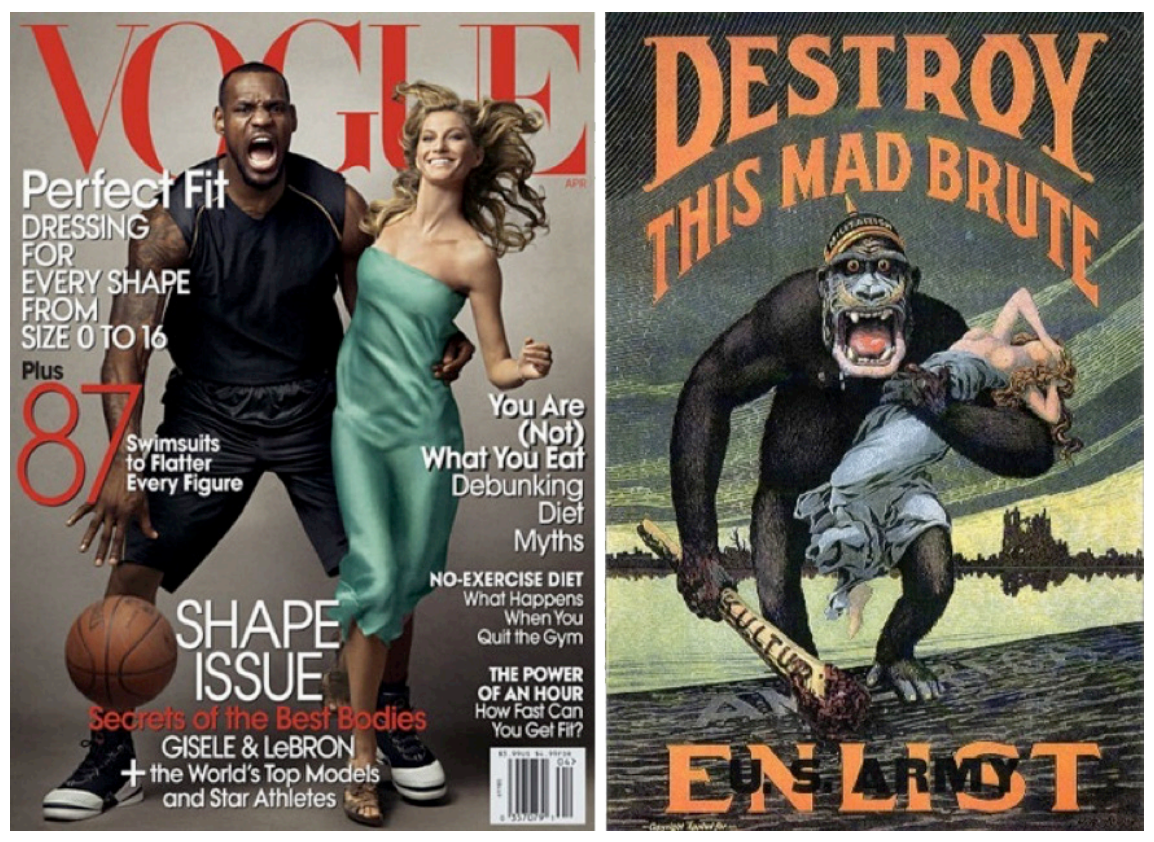

Figuras 5 e 6. Capa da Vogue América, April 2008 e Cartaz, norte-americano, de 1917, a recrutar militares para a primeira guerra mundial. In: Shea, D. (2008).

Grande parte dos hábitos passam despercebidos e incólumes pela nossa mente, por isso, temos de fazer um esforço acrescido para os notarmos como nossos e não necessariamente de todos. Mas se é difícil detetarmos e legitimarmos pontos de vistas alternativos, quando confrontados com produtos mediáticos isolados, mais árdua se torna a tarefa em torno de discursos inteiros.

Barthes (2001) fala na necessidade de "desmistificação [das] falsas evidências", de "recuperar na exposição decorativa do-que-é-óbvio, o abuso ideológico que ... nele se dissimula" e da recusa da tautologia, "desse "porque sim" imperativo que os pais, que ignoram as respostas, suspendem sobre a cabeça dos filhos" (p. 7-8, 174). Estes argumentos encontram eco no conceito de "doxa", que Bourdieu (1977) define como sendo o "universo daquilo que não é discutido, mencionado, daquilo que é admitido sem argumento ou escrutínio" (p. 170).

\section{Considerações finais}

A mobilidade geográfica e social fez com que as pessoas deixassem de estar confinadas a categorias anteriormente definidas como um país ou estrato social. 0 globo é hoje um complexo mosaico que tende, por vezes, a camuflar problemáticas em torno da discriminação, diferença e das desigualdades no acesso ao espaço público. Apesar da multiculturalidade e diversidade fazer cada vez mais parte das agendas políticas, a questão da 'raça' continua a levantar contendas e a encerrar em si muitos silêncios, ambiguidades e jogos de poder. Um dos campos de análise mais profuso para a constatação dessas dinâmicas é o das representações mediáticas. 
A temática da 'raça' não se circunscreve apenas a 'brancos' e 'negros'. A fixidez dos pólos, embora exclua injustamente muitas nuances, facilita no explanar de certos pontos de vista que, a meu ver, são paradigmáticos nas discussões em torno das relações étnicas.

0 que se pretendeu com este artigo foi chamar a atenção para o fato de que devemos procurar discursos alternativos e ter um "olho etnográfico", que "significa que nos devemos esforçar ao máximo para tornar o familiar 'estranho' " (Holliday et al., 2004: 200). Devemos estar em alerta para "os perigos do discurso falsamente polifónico, que marginaliza e enfraquece certas vozes para em seguida fingir um diálogo com uma entidade-fantoche já enfraquecida por diversas falsificações..." (Shohat e Stam, 2006: 312). Só assim conseguiremos, mais do que aceitar, entender e respeitar a diferença.

REFERÊNCIAS BIBLIOGRÁFICAS

Barker, C. (2000). Cultural Studies. Thousand Oaks: SAGE.

Barros, Z. et al. (2011). Educação e Relações Étnico-Raciais. Salvador: Centro e Estudos Afro-

-Orientais, Universidade Federal da Bahia. In: (http://209.177.156.169/libreria_cm/archivos/ pdf_256.pdf) (acedido 19/11/2014).

Barthes, R. (2001). Mitologias. $11^{\text {a }}$ ed. Rio de Janeiro: Bertrand.

Baudrillard, J. (1991). Simulacros e Simulações. Lisboa: Relógio d’Água.

Bernstein, A. (2002). Representation, Identity and the Media. In: Newbold, C. et al. (ed.) The Media Book. London: Arnold.

Bonilla-Silva, E. (2003). Racism without Racists: Color-Blind Racism and the Persistence of Racial Inequality in the United States. Lanham, MD: Rowman and Littlefield Publishers.

Bourdieu, P. (1977). Outline of a Theory of Practice. Cambridge: CUP.

Brooks, D. \& Hébert, L. (2006). Gender, Race, and Media Representation. In: Dow, B. \& Wood, J.

(eds.) The SAGE Handbook of Gender and Communication. Thousand Oaks: SAGE.

Bruce, S. \& Yearley, S. (2006). The Sage Dictionary of Sociology. Thousand Oaks: SAGE.

Emmanuel, K. (2014). While We Battle the Violence of UNFAIR Advertising.... In: http://darkisbeautiful.blogspot.pt/ (acedido 13/07/2016)

Fanon, F. (1956). Racismo e Cultura. In: Sanches, M. (ed.). (2011). Malhas que os Impérios Tecem. Lisboa: Edições 70.

Ferguson, R. (2004). The Media in Question. London: Arnold.

Fiske, J. (1987). Television Culture. London: Routledge.

Gaines, E. (2010). Media Literacy and Semiotics. New York: Palgrave Macmillan.

Gallagher, C. (2007). White. In: Vera, H. \& Feagin, J. (eds.) Handbook of the Sociology of Racial and Ethnic Relations. New York: Springer.

Hall, S. (1980). Estudos Culturais: Dois Paradigmas. In: Hall, S. (2003). Da Diáspora. Belo Horizonte: Editora UFMG.

Hall, S. (1981). The Whites of Their Eyes. Racist Ideologies and the Media. In: Dines, G. \& Humez, J. (eds.). (1995). Gender, Race and Class in Media. Thousand Oaks: SAGE.

Hall, S. (1992). Race, Culture, and Communications: Looking Backward and Forward at Cultural Studies. Rethinking MARXISM. Vol. 5(1).

Holliday, A. et al. (2004). Intercultural Communication. London: Routledge.

Hooks, B. (1992). Eating the Other: Desire and Resistance. In: Black Looks: Race and Representation. Boston: South End Press. 
Jardim, C. (2016). "Você só precisa ser branca para vencer": propaganda de creme branqueador gera polêmica. In: (http://www.bbc.com/portuguese/noticias/2016/01/160109_publicidade_ brancos_tailandia_cj_lab) (acedido 06/09/2016)

Jones, M. \& Jones, E. (1999). Mass Media. London: MacMillan Press Ltd.

Kellner, D. (2001). A Cultura da Mídia. São Paulo: EDUSC.

Marketeer. (2016). Elvive e Ana Sofia contra ditadura dos cabelos lisos. In: (http://marketeer. pt/2016/03/10/elviveeanasofiacontraditaduradoscabeloslisos/) (acedido 21/12/2016).

Matless, D. (2009). Reflexivity. In: Gregory, D. et al. (eds.) The Dictionary of Human Geography. 5th ed. Chichester: Wiley Blackwell.

Miller, T. (2006). What it is and what it isn't: Introducing.... Cultural Studies. In: Miller, T. (eds.) A Companion to Cultural Studies. Chichester: Wiley Blackwell.

Notícias ao Minuto (2014). Emirados Árabes Unidos baniu o filme 'Exodus'. In: (http://www.noticiasaominuto.com/cultura/326826/emirados-arabes-unidos-baniu-o-filme-exodus) (acedido 29/12/2014).

Ott, B. \& Mack, R. (2014). Critical Media Studies. 2nd ed. Chichester: Wiley Blackwell.

Peirce, C. (1877). A fixação da crença. Popular Science Monthly 12. New York: D. Appleton \& Company. In: (http://bocc.ubi.pt/pag/peirce-charles-fixacao-crenca.html) (acedido 06/01/2015).

Phillips, A. (2010). What's wrong with essentialism? Distinktion: Scandinavian Journal of Social Theory. 11(1): 47-60. In: (http://eprints.Ise.ac.uk/30900/1/What\%27s\%20wrong\%20with\%20 essentialism\%20\%28LSERO\%29.pdf) (acedido 02/11/2014).

Prata, S. (2014). Iconoclasmo. In: (http://www.sergioprata.com.br/port/iconoclasmo.html) (acedido 29/12/2014).

Saussure, F. (2006). Curso de Linguística Geral. São Paulo: Cultrix.

Shea, D. (2008). Uncovered: Possible Inspiration For Controversial LeBron James Vogue Cover. In: (http://www.huffingtonpost.com/2008/03/28/uncovered-possible-inspir_n_93944.html) (acedido 03/12/2014).

Shohat, E. \& Stam, R. (2006). Crítica da Imagem Eurocêntrica. São Paulo: Cosac Naify.

The Guardian (2010). KFC accused of racism over Australian advertisement. In: (http://www.theguardian.com/business/2010/jan/06/kfc-advertisement-accused-of-racism) (acedido 29/12/2014).

Van Dijk, T. (2000). New(s) Racism: A discourse analytical approach. In: Cottle, S. (eds.) Ethnic Minorities and the Media. Buckingham: OUE.

Visão. (2011). Anúncio da Nivea gera polémica e acusações de racismo. (In: http://visao.sapo.pt/ actualidade/sociedade/anuncio-da-nivea-gera-polemica-e-acusacoes-de-raciscmo=f618314) (acedido 04/11/2014).

Weber, L. (1998). A Conceptual Framework for Understanding Race, Class, Gender, and Sexuality. Psychology of Woman Quarterly, 22(13-23). Cambridge: CUP.

Wolton, D. (2012). Doing Cultural Theory. Thousand Oaks: SAGE.

Sónia Marques - Doutoranda em Ciências da Comunicação na Universidade de Coimbra. Docente e coordenadora do Gabinete de Comunicação da Universidade Gregório Semedo, em Luanda (Angola).

Data de recepção do artigo/ Received for publication: 28.12.2016

Data de aceitação do artigo/ Accepted in revised form: 22.02.2017 